\title{
Mental health services for adults with learning
}

\section{disabilities}

\author{
NICK BOURAS and GER ALDINE HOLT
}

Services for people with learning disabilities have been transformed since the late 1960s by the move from institutional to community care. (Learning disabilities is the term currently used in the UK in preference to mental retardation, developmental disabilities and mental handicap.) Important changes include the progress towards integration, participation, inclusion and choice for people with learning disabilities, which have occurred in the context of the broader civil and human rights movements. It is time to examine the services delivered to people with learning disabilities and comorbid psychiatric disorders (mental illness, personality disorders, behavioural problems with aggression) and the evidence for their effectiveness.

Psychiatric disorders are more prevalent in adults with learning disabilities than in the general population (Deb et al, 2001). These disorders frequently go undetected and thus untreated. Appropriate services are often lacking in availability, accessibility and adequacy. Indecision, ambiguity and confusion concerning mental health services for people with learning disabilities have been noted (Hassiotis et al, 2000). Many service planners wrongly assumed that returning these people from residential institutions to community care programmes would reduce the prevalence of psychiatric disorders in this group. Although demands on mental health services by people with learning disabilities have in fact increased following their resettlement, the additional clinical services and resources have not been forthcoming (Royal College of Psychiatrists, 2003). The outcome is that several thousand people with learning disabilities and psychiatric disorders have been placed in residential facilities out of their place of origin (Department of Health, 2001a).

\section{WHO SHOULD PROVIDE CARE?}

In some quarters it was previously believed that the psychiatric care of people with learning disabilities should be undertaken by mainstream mental health services. This is a long-standing government policy (Department of Health, 2001b), and the argument for this approach appears sound and is supported widely. It is, for example, current policy in the USA. However, in practice mainstream community mental health teams have found it increasingly difficult to meet the needs of people with learning disabilities and psychiatric disorders (US Public Health Service, 2002).

Advocates of normalisation support the mainstream approach, arguing that specialised services lead to stigmatisation, labelling and negative professional attitudes. Others have demonstrated that special expertise is required for the diagnosis and treatment of psychiatric disorders in this population. They have argued for specialis mental health teams, pointing out that although it is theoretically possible to train staff in mainstream settings, the small number of cases gives little opportunity for staff in the various disciplines to gain the necessary skills. Additionally, mainstream staff often feel that such care is not part of their role, and the resources of adult mental health services are already stretched (Day, 1988). Problems arise particularly over admissions to adult acute in-patient units, as people with learning disabilities often require a longer stay and may be vulnerable without additional support on the ward. Furthermore, people with learning disabilities represent a heterogeneous group with a varied range of complex mental health needs, which mainstream staff may feel ill-equipped to meet.

Service responses have as a result varied both nationally and internationally. They include provision from mainstream mental health care services, including in-patient admissions; a specialist mental health service for people with learning disabilities provided as part of the mainstream mental health service, with specialist in-patient beds; and a specialist learning disabilities service, with several functions (such as skill development and needs assessment, including mental health care), with or without in patient beds (Bouras \& Jacobson, 2002).

The most common form of care in England has been provided by community learning disability teams, often led by social services, with multiprofessional staff who provide a range of inputs, including physical and mental health care, resettlement and social care. The role of community learning disability teams is undergoing review, and the White Paper Valuing People (Department of Health, 2001b) proposes that these teams should enable access to mainstream services as much as possible. This means that the mainstream mental health services will increasingly be required to care for people with learning disabilities and psychiatric disorders. The provision of mental health care by community learning disability teams - both in terms of enabling access to mainstream mental health services, and delivering highly specialist assessment and treatment for those with more complex needs - is compromised by the current boundary disputes between learning disability services and mainstream mental health services, and the consequent financial implications. These problems extend to people with learning disabilities, who may have additional forensic mental health problems, people with autistic disorders, Asperger syndrome or significant social impairment, and those with borderline intellectual deficits.

\section{WHAT IS THE EVIDENCE- BASED PRACTICE?}

The current evidence base for the organisation and delivery of mental health care for people with learning disabilities is inconclusive and inconsistent. It relies largely on retrospective reports and uncontrolled studies with small numbers of participants (Chaplin, 2004). However, there are a handful of randomised controlled trials. A Dutch study showed a reduction in hospitalisation from a service provided by a community learning disability team (Van Minnen et al, 1997). Intensive case management provided in a special programme by a mainstream community mental health team in the USA improved adaptive functioning in a group of people with learning disabilities and psychiatric disorders (Coelho et al, 1993). In both 
studies the sample size was small. A subgroup of people with borderline cognitive impairment in the UK700 study were found to have spent significantly less time in hospital if they had received intensive community care (Tyrer et al, 1999). This was an unintentional finding, as the study was not designed for a population with learning disabilities.

Fraser (2000) referred to the developments in learning disability services as the 'Age of Enlightenment', based on strong ideological and political views, although the evidence is still awaited. Moss et al (2000) postulated a matrix model for the development and evaluation of mental health services for people with learning disabilities, describing inputs, processes and outputs at national, local and service user level. Systematic evaluation and exploratory clinical trials (Campbell et al, 2000) might be more appropriate at present for research into mental health services for people with learning disabilites. This would allow greater understanding of the services that are already in place to deliver care and their variations, and would lead to evaluative research about best practices. The application of randomised controlled trials to evaluate health and socially complex interventions has to overcome major methodological problems (Wolf, 2000), particularly in learning disability services (Oliver et al, 2002). A further problem is that bodies funding mental health research tend to consider the area of mental health for people with learning disabilities as the responsibility of learning disability organisations and vice versa. The result is that no one is interested in supporting research studies in this area. In the meantime an alliance is necessary between academic institutions, health and social care providers, charities, carers and service user groups to develop a research strategy that will promote evidence-based practice.

\section{ATERTIARY SERVICE}

The specialisation of mental health services for people with learning disabilities, provided by mainstream mental health services at a tertiary care level, offers a way forward. Such a solution should be instrumental in surmounting the bureaucratic

NICK BOURAS, MD, PhD, FRCPsych, GERALDINE HOLT, MBBS, BSc, FRCPsych, Guy's, King's and St Thomas' Medical School and the Institute of Psychiatry, London, UK

Correspondence: Professor N. Bouras, Estia Centre, York Clinic, Guy's Hospital, 47 Weston Street, London SEI 3RR, UK

(First received 6 June 2003, final revision 21 August 2003, accepted 7 October 2003)

barriers to care at all service levels. It would bridge the gulf between service systems and would endorse working within the National Framework for Mental Health as well as sharing resources and expertise. This service model would be compatible with other tertiary mental health services such as home treatment teams, assertive outreach services, eating disorders teams and early intervention teams for psychosis. The clinical interface between mental health and learning disability services should follow the pattern of that existing between child development teams and child and adolescent mental health teams, and old age mental health teams and geriatric services.

\section{DECLARATION OF INTEREST}

None.

\section{ACKNOWLEDGEMENTS}

We are grateful to Dr Jed Boardman, Professor Gregory O'Brien and Dr Kiriakos Xenitidis for their comments.

\section{REFERENCES}

Bouras, N. \& Jacobson, J. (2002) Mental health care for people with mental retardation: a global perspective. World Psychiatry, I, 162-165.

Campbell, M., Fitzpatrick, R., Haines, A., et al (2000) Framework for design and evaluation of complex interventions to improve health. BMJ, 32I, 694-696.

Chaplin, R. (2004) General psychiatric services for adults with intellectual disability and mental illness: a review. Journal of Intellectual Disability Research, 48, I-8.

Coelho, R. J., Kelley, P. S. \& Deatsman-Kelly, C. (1993) An experimental investigation of an innovative community treatment model for persons with dual diagnosis (DD/MI). Journal of Rehabilitation, 54, 37-42.

Day, K. (1988) Services for psychiatrically disordered mentally handicapped adults. Australia and New Zealand Journal of Developmental Disabilities, 14, 19-25.
Deb, S., Thomas, M. \& Bright, C. (200I) Mental disorder in adults with intellectual disability: prevalence of functional psychiatric illness among a communitybased population aged between 16 and 64 years. Journal of Intellectual Disability Research, 45, 495-505.

Department of Health (200la) From Words into Action: London Learning Disabilities Strategic Framework. London: Stationery Office.

Department of Health (200Ib) Valuing People: A New Strategy for Learning Disability for the 2lst Century. London: Stationery Office.

Fraser, w. (2000) An Age of Enlightenment. In The New Oxford Textbook of Psychiatry (eds M. G. Gelder, J. J. Lopez-lbor \& C. Andreasen), pp. 1931-1934. Oxford: Oxford University Press.

Hassiotis, A., Barron, P. \& O'Hara, J. (2000) Mental health services for people with learning disabilities. BMI, 32I, 583-584.

Moss, S., Bouras, N. \& Holt, G. (2000) Mental health services for people with intellectual disability: a conceptual framework. Journal of Intellectual Disability Research, 44, 97-107.

Oliver, P. C., Piachaud, J., Done, J., et al (2002) Difficulties in conducting a randomised controlled trial of health service interventions in intellectual disability: implications for evidence-based practice. Journal of Intellectual Disability Research, 46, 340-355.

Royal College of Psychiatrists (2003) Meeting the Mental Health Needs of Adults with a Mild Learning Disability (Council Report CRII5). London: Royal College of Psychiatrists.

Tyrer, P., Hassiotis, A., Ukoumunne, O., et al (1999) Intensive case management for psychotic patients with borderline intelligence: UK700 Group. Lancet, 354, 999-1000.

US Public Health Service (2002) Closing the Gap: A National Blueprint for Improving the Health of Individuals with Mental Retardation. Report of the Surgeon General's Conference on Health Disparities and Mental Retardation. Washington, DC: US Department of Health and Human Services.

Van Minnen, A., Hoogduin, C. A. L. \& Broekman, T. G. (1997) Hospital vs. outreach treatment of patients with mental retardation and psychiatric disorders: a controlled study. Acta Psychiatrica Scandinavica, 95, 515-522.

Wolf, N. (2000) Using randomised controlled trials to evaluate socially complex services: problems, challenges and recommendations. Journal of Mental Health Policy and Economics, 3,97-109. 